\title{
Interrupted Aza-Wittig Reactions Using Iminophosphoranes to Synthesize ${ }^{11}$ C-Carbonyls
}

Uzair S. Ismailani, ${ }^{1,2}$ Maxime Munch, ${ }^{1,2}$ Braeden A. Mair, ${ }^{2,3}$ and Benjamin H. Rotstein ${ }^{1,2,3 *}$

${ }^{1}$ Department of Biochemistry, Microbiology and Immunology, University of Ottawa

${ }^{2}$ University of Ottawa Heart Institute

${ }^{3}$ Department of Chemistry and Biomolecular Sciences, University of Ottawa

Correspondence: Benjamin H. Rotstein, $\mathrm{PhD}$

University of Ottawa Heart Institute

40 Ruskin Street, H-5219

Ottawa, Ontario, Canada

K1Y 4W7

Phone: 613-696-7324

Email: benjamin.rotstein@uottawa.ca 


\begin{abstract}
Carbonyls are frequently found in bioactive compounds due to their propensity for hydrogen bonding and synthetic utility in functional group manipulations. Carbon-11 $\left({ }^{11} \mathrm{C}\right)$ is routinely incorporated into small molecule radiotracers for positron emission tomography (PET) imaging. Herein, we report a high-yielding, direct $\mathrm{CO}_{2}$-fixation methodology coupling structurally diverse iminophosphoranes with various nucleophiles to synthesize ureas, carbamates, thiocarbamates, and amides, and which is amenable for ${ }^{11} \mathrm{C}$ radiolabeling. The success of this strategy relies upon the interception of an isocyanate intermediate of sequential aza-Wittig reactions using a suitable nucleophile. This methodology is practical, as demonstrated by the synthesis of $>35$ products and isolation of the radiopharmaceuticals $\left[{ }^{11} \mathrm{C}\right] \mathrm{URB} 694$ (13\% radiochemical yield, $\left.69 \mathrm{GBq} \cdot \mu \mathrm{mol}^{-1}\right)$ and $\left[{ }^{11} \mathrm{C}\right]$ glibenclamide $\left(62 \% \mathrm{RCY}, 59 \mathrm{GBq} \cdot \mu \mathrm{mol}^{-1}\right)$, within 17 minutes and 21 minutes from $\left[{ }^{11} \mathrm{C}\right] \mathrm{CO}_{2}$, respectively.
\end{abstract}

\title{
Introduction
}

Positron emission tomography (PET) is a non-invasive molecular imaging modality used to evaluate biological processes in vivo with short-lived radionuclides. PET radiopharmaceuticals are used to diagnose metastatic and cardiovascular diseases, conduct non-invasive pathology studies to detect biomarkers of neurodegeneration, and to probe molecular and functional mechanisms in living systems. ${ }^{1}$ Carbon- $11\left({ }^{11} \mathrm{C}, t_{1 / 2}=20.4 \mathrm{~min}\right)$ is prized for isotopic labeling of biomolecules and pharmaceuticals, and is routinely incorporated into PET imaging agents for both research and clinical applications. ${ }^{2,3}$ Currently, a lack of diverse methods for directly incorporating $\left[{ }^{11} \mathrm{C}\right] \mathrm{CO}_{2}$ into complex molecules has limited its use. ${ }^{4}$ Consequently, $\left[{ }^{11} \mathrm{C}\right] \mathrm{CO}_{2}$ is most often converted into reactive secondary precursors such as $\left[{ }^{11} \mathrm{C}\right] \mathrm{CH}_{3} \mathrm{I}$ or $\left[{ }^{11} \mathrm{C}\right] \mathrm{CH}_{3} \mathrm{OTf}$, which are accompanied by elongated processing times and significant reductions in radiochemical yield due 
to sub-quantitative conversions. ${ }^{5-8}$ Isocyanates are valuable synthetic intermediates that can be readily converted into pharmaceutically-relevant functional groups such as carbamates, ureas, and amides. ${ }^{9,10}$ Conventional approaches to synthesizing ${ }^{11} \mathrm{C}$-isocyanates rely on stepwise trapping of $\left[{ }^{11} \mathrm{C}_{\mathrm{CO}_{2}}\right.$ with amines, followed by dehydration using phosphoryl chloride ( $\left.\mathrm{POCl}_{3}\right)$ or Mitsunobutype conditions. ${ }^{4,11,12}$ Importantly, the former strategy displays poor tolerance towards anilines and the highly acidic conditions pose challenges for maintaining efficient trapping of $\left[{ }^{11} \mathrm{C}^{-} \mathrm{CO}_{2}\right.$ in solution. The latter technique has displayed improved utility for synthesizing asymmetrical ureas ${ }^{12}$ and also amides using either Grignard reagents ${ }^{13}$ or organozinc coupling reactions, ${ }^{14}$ though high mass loading of azo reagents and phosphines may complicate radiotracer purification. Each strategy requires careful control of temperature and reagent concentrations during sequential reaction steps in order to prevent formation of complex mixtures of symmetrical byproducts and heterocycles. ${ }^{11,15}$ Iminophosphoranes have been shown to undergo the aza-Wittig reaction directly with $\mathrm{CO}_{2}$ to produce isocyanates in high yields. ${ }^{16}$ Indeed, similar reactivity towards carbonyl containing functional groups has been exploited in the synthesis of complex alkaloids such as (-)dendrobine and a myriad heterocyclic drugs and natural products. ${ }^{17,18}$ In the context of ${ }^{11} \mathrm{C}$, the commercially available precursor $N$-(triphenylphosphoranylidene)aniline was previously reported to prepare acyclic ${ }^{11} \mathrm{C}$-ureas from $\left[{ }^{11} \mathrm{C}_{C} \mathrm{CO}_{2}\right.$ in moderate radiochemical yields (RCYs). ${ }^{19}$ Del Vecchio et al. deployed $o$-azidoanilines and azido alcohols with dimethylphenylphosphine to synthesize cyclic ureas and carbamates, including oxatomide, domperidone, and zolmitriptan in useful yields through a proposed intramolecular Staudinger aza-Wittig sequence (SAW, Scheme 1a) upon heating to $70{ }^{\circ} \mathrm{C}^{20,21} \mathrm{An}$ intermolecular variant of this reaction produced a linear carbamate in low RCY at much higher temperature. 
We aimed to develop conditions that are high yielding and selective for $\mathrm{C}-\mathrm{O}, \mathrm{C}-\mathrm{N}, \mathrm{C}-\mathrm{C}$, and $\mathrm{C}-\mathrm{S}$ bond formation and would be amenable for one-pot $\left[{ }^{11} \mathrm{C}\right] \mathrm{CO}_{2}$-fixation to prepare radiopharmaceuticals and novel tracer candidates. Through the synthesis of functionalized iminophosphorane precursors, this approach would obviate the need for highly acidic $\mathrm{POCl}_{3}$, Mitsunobu reagents, explosive azide precursors, and toxic phosphines used in current methodologies, enhancing the substrate versatility and practicality of this method for good manufacturing practices (GMP) environments (Scheme 1b). Herein, we describe a versatile and efficient approach to carbonyl ligation using iminophosphorane- $\mathrm{CO}_{2}$-fixation coupled with intermolecular nucleophilic addition. This method is effective for synthesizing acyclic products with stable isotopes under mild conditions and is suitable for automated synthesis and ${ }^{11} \mathrm{C}$ radiolabeling. We demonstrate a broad substrate scope, high functional group tolerance, and practical application for the synthesis and isolation of radiopharmaceuticals.

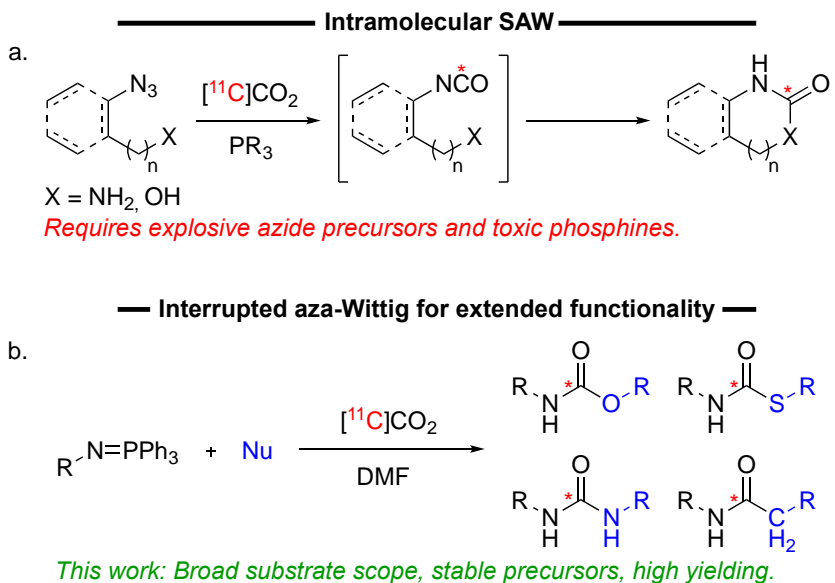

Scheme 1. Synthetic approaches to iminophosphorane $\left[{ }^{11} \mathrm{C}_{\mathrm{CO}_{2}}\right.$-fixation.

\section{Results and Discussion}

At the outset, we focused on developing a nucleophilic coupling strategy to iminophosphorane$\mathrm{CO}_{2}$ fixation conditions using stable isotopes, since no such straightforward high yielding 
procedure for this coupling has been reported. ${ }^{16}$ First, $\mathrm{CO}_{2}$ was bubbled into a heated toluene solution containing $N$-(triphenylphosphoranylidene)aniline (1a) until complete consumption of the iminophosphorane, followed by the addition of benzyl alcohol (2).

Table 1. Optimization of reaction conditions

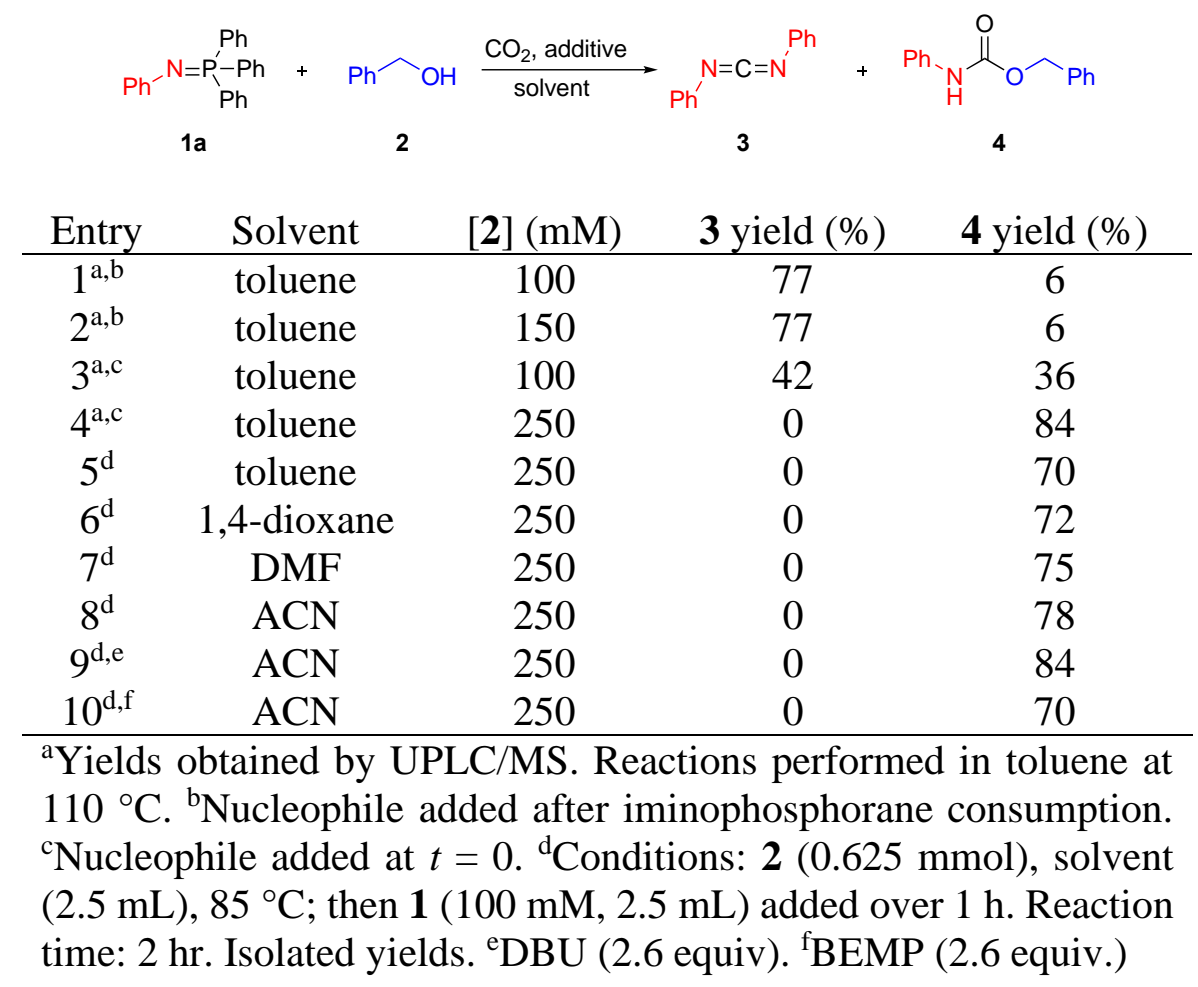

Low yield of the desired product $4(6 \%)$ was observed using stepwise addition (Table 1, entry 1). The observed major product was the symmetrical $N, N^{\prime}$-diphenylcarbodiimide (CDI, 3), likely formed by a second aza-Wittig coupling reaction to the isocyanate intermediate. ${ }^{18}$ The ratio of $4: 3$ increased to 0.9:1 when the nucleophile was present from the beginning of the reaction (entry 3). Increasing the concentration of 2 led to exclusive formation of $\mathbf{4}$ in $84 \%$ yield (entry 4). This suggests that short-lived free isocyanates are formed in the presence of iminophosphoranes, subject to two competing reaction pathways: CDI formation and carbamate formation. Thus, at high 
concentrations of an intercepting nucleophile, it is possible to selectively divert the reaction towards intermolecular ligation. Carbamate $\mathbf{4}$ could be prepared and isolated in good yields from hydrocarbon, ethereal, and polar solvents using similar conditions (entries 5-8). With our primary focus on establishing easily translatable conditions to ${ }^{11} \mathrm{C}$ radiochemistry, we were delighted to find that two common $\mathrm{CO}_{2}$ trapping bases, amidine DBU and phosphazene BEMP (2.6 equiv.), significantly increased the rate of formation of $\mathbf{4}$, concomitant with moderate impacts in yield (entries 9-10, table $\mathrm{S} 1$ ). These effects are likely due to the increased availability of soluble $\mathrm{CO}_{2}$ in the form of activated complexes..$^{22,23}$

We assessed the compatibility of the iminophosphorane- $\mathrm{CO}_{2}$-fixation method with a diverse scope of nucleophiles (Scheme 2a). Under our developed conditions, carbamates derived from benzyl, isopropyl, and 4-methoxyphenethyl alcohol were isolated in 84-94\% yields (4-6). In contrast, phenyl carbamates and thiocarbamates (7-9) required higher nucleophile concentrations to achieve yields in excess of 70\%, likely due to their propensity for elimination. Benzyl mercaptan also proved to be a compatible nucleophile, forming the corresponding thiocarbamate $\mathbf{1 0}$ in excellent yield (86\%). Sterically hindered nucleophiles such as tert-butanol yielded product $\mathbf{1 1}$ $(83 \%)$ in high yield, and $N$-methyl- $N$-tert-butylamine also provided the urea $\mathbf{1 2}$ in $78 \%$ yield. We were gratified to find that amides such as $\mathbf{1 3}(82 \%)$ could be accessed directly by carbon-carbon bond formation using diethyl malonate. Despite this success, some nucleophiles were found to be incompatible with the interrupted aza-Wittig conditions, including Grignard reagents, and phenylacetylene. However, a number of our synthesized products $(\mathbf{7 - 9}, \mathbf{1 1 - 1 2})$ stand in as blocked isocyanates, and facilitate indirect nucleophilic substitution (Scheme 2b). ${ }^{24}$ In situ formed $O$ phenylcarbamate $\mathbf{7}$ could be successfully transformed to amides 14-16, all in moderate to good 
yields based on iminophosphorane 1a. Overall, both direct and indirect nucleophilic substitutions are robust, and further open the door to selective $\mathrm{C}-\mathrm{C}$ bond formation using iminophosphoranes. We next investigated the scope of functionalized aryl iminophosphoranes synthesized by the Kirsanov reaction and isolated by our modified general procedure (Scheme 2c, see ESI for details).$^{18}$ First, CBz-protected products (17-21) were isolated to determine sensitivity to electronic and steric features of iminophosphoranes under the optimized conditions. Electron-rich arenes, aryl bromides, and ortho-substitution $(\mathbf{1 7 - 1 8}, \mathbf{2 1})$ were all well-tolerated in comparison with electron-deficient iminophosphoranes (19-20). Alkyl iminophophosphoranes afforded products such as carbamate $\mathbf{2 2}(82 \%)$ and blocked isocyanates $\mathbf{2 3 - 2 4}$ in good yields. The utility of this method for biopharmaceuticals was assessed by targeting the fatty acid amide hydrolase inhibitor URB694 (25), melatonin (26), and the oral multi-kinase inhibitor regorafenib (29). Hydroquinone carbamate 25 was isolated as a mixture of regioisomers in $60 \%$ yield. ${ }^{11}$ Indirect substitution using phenol-blocked isocyanates yielded melatonin 26 (72\%), phenylalanine derivative 27 (84\%), and electron-deficient amide $\mathbf{2 8}$ (73\%). Finally, the urea regorafenib 29 was synthesized first by direct nucleophilic coupling, though indirect substitution using an $N$-tert-butylmethylamine blocked isocyanate intermediate better facilitated purification of $\mathbf{2 9}$ in $71 \%$ overall yield. ${ }^{25}$ 
Scheme 2: Interrupted aza-Wittig for Extended Functionality: Reaction Scope

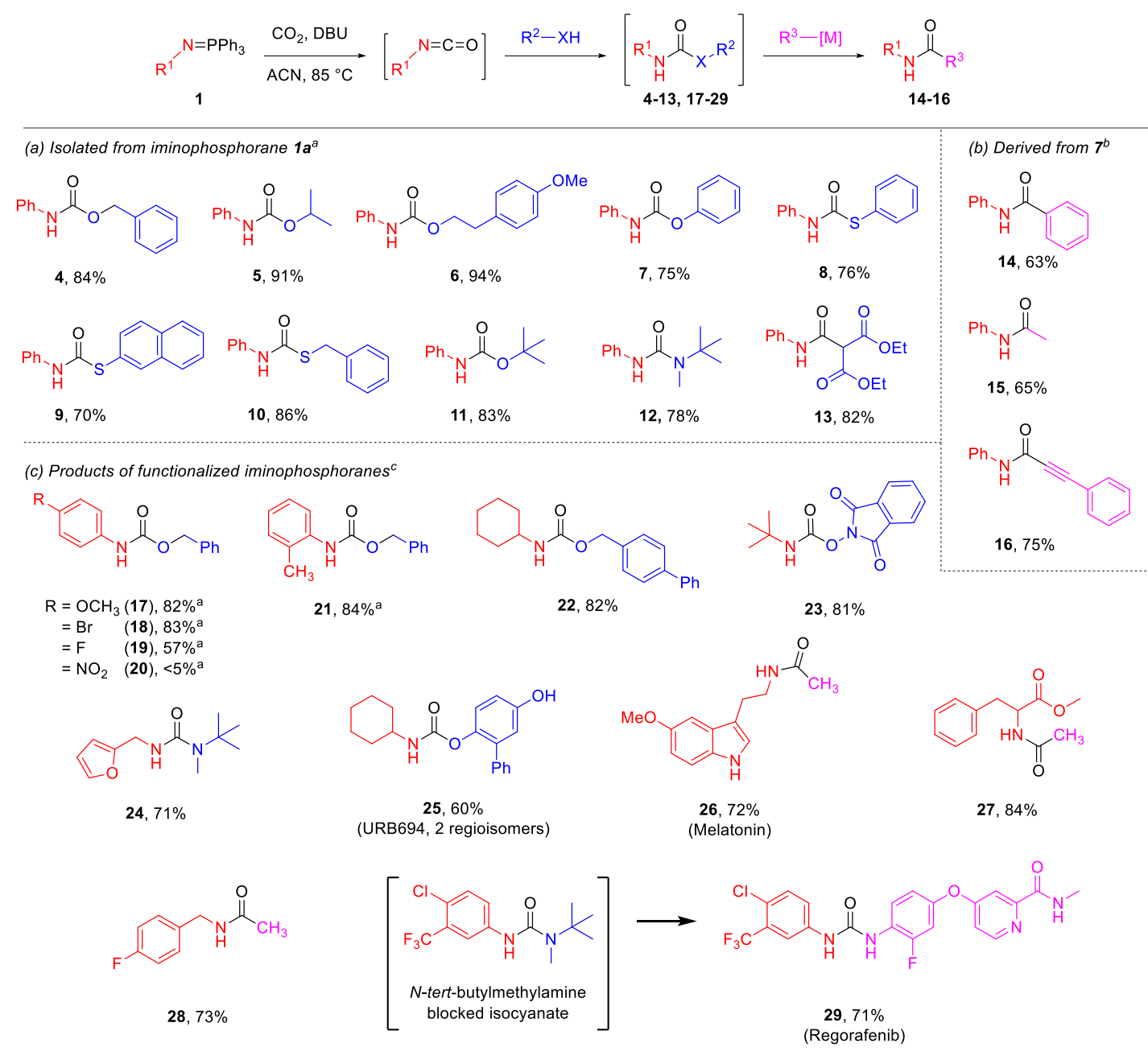

${ }^{\mathrm{a} C}$ Conditions: 1 (0.25 mmol), $\mathrm{R}^{2}-\mathrm{XH}$ (2.5 equiv.), DBU (2.6 equiv.), ACN (2.5 mL),

reflux; isolated yields. ${ }^{b} \mathrm{PhOH}$ (10 equiv.), $\mathrm{R}^{3}-\mathrm{MgX}$ (20 equiv.) or $\mathrm{R}^{3}$-SH (2.5 equiv.) or PhCCH (12 equiv.), THF. ${ }^{c} \mathrm{R}^{2}$-XH (10 equiv.), LHMDS (0.99 equiv.), THF. See ESI for detailed procedures.

Satisfied with the iminophosphorane- $\mathrm{CO}_{2}$ nucleophilic coupling methodology using stable isotopes, we were determined to apply this method to carbon- 11 radiochemistry. Since $\left[{ }^{11} \mathrm{C}_{C} \mathrm{CO}_{2}\right.$ is the limiting reagent in these processes (typically $<1 \mu \mathrm{mol}$ ), reconsideration of reaction 
conditions to produce $\left[{ }^{11} \mathrm{C}\right] 4$ was required (Table 2). First, we focused on the influence of the concentration of 1a on product yield using high concentrations of DBU and benzyl alcohol in ACN (entry 1). We noted a low $13 \%$ RCY with these initial conditions, mainly due to a large excess of unreacted $\left[{ }^{11} \mathrm{C}_{\mathrm{CO}_{2}}\right.$. Increasing the concentration of 1a (entries 2-3) led to maximum $32 \%$ RCY and reducing the concentration of DBU to $100 \mathrm{mM}$ enhanced the selectivity toward $\left[{ }^{11} \mathrm{C}\right] 4$ (entry 4-5). Increasing the reaction temperature in DMF to $100{ }^{\circ} \mathrm{C}$ resulted in $65 \%$ RCY (entries 6-7). Finally, increasing the concentration of nucleophile 2 further improved the selectivity of $\left[{ }^{11} \mathrm{C}\right] \mathbf{4}$, leading to a $91 \%$ RCY (entries 7-9). Trapping efficiencies of $\left[{ }^{11} \mathrm{C}\right] \mathrm{CO}_{2}$ during the optimization of $\left[{ }^{11} \mathrm{C}\right] 4$ were all greater than $90 \%$.

Table 2. Radiochemistry Optimization

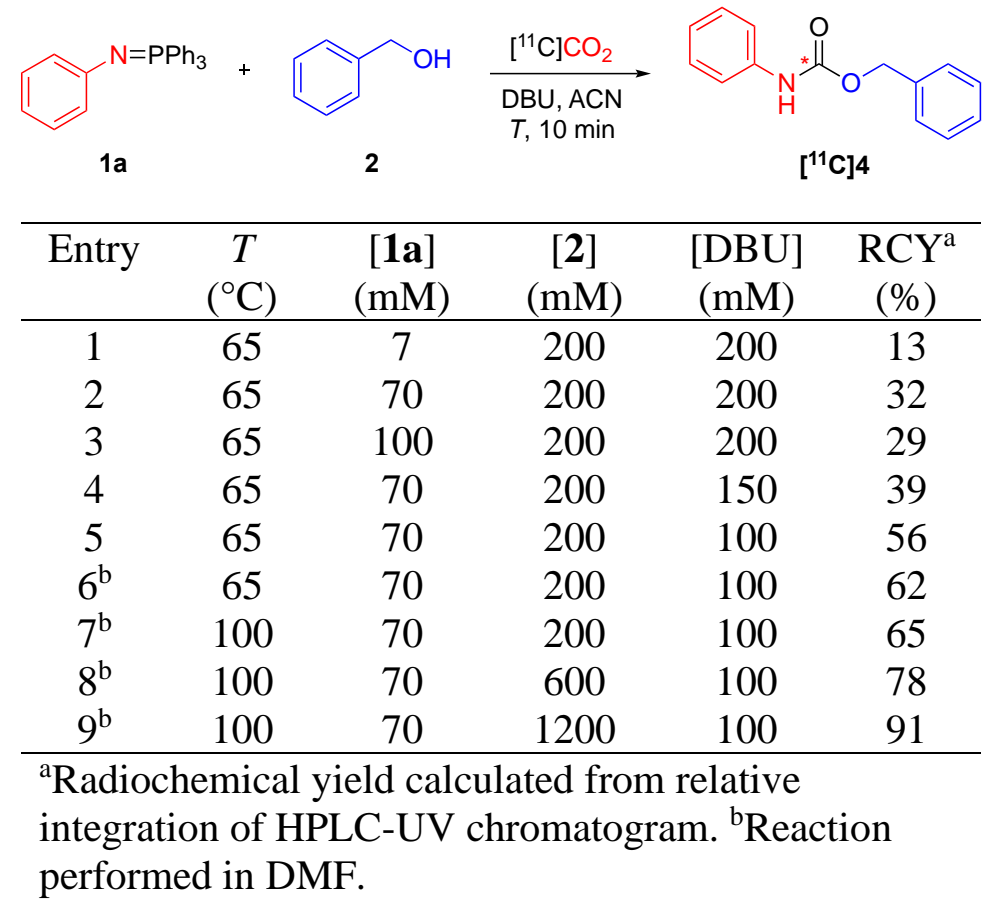

Structurally diverse iminophosphoranes were also used to successfully radiolabel compounds using this procedure (Scheme 3). Aniline derived products using iminophosphorane 1a include labeled urea $\left[{ }^{11} \mathrm{C}\right] 30$ in $88 \% \mathrm{RCY}$, and blocked isocyanate $\left[{ }^{11} \mathrm{C}\right] 12$ in $32 \% \mathrm{RCY}$. Using 
benzyl iminophosphorane, $O$-benzyl carbamate $\left[{ }^{11} \mathrm{C}\right] \mathbf{3 1}$ was formed in $64 \%$ yield. By substituting DABCO for DBU, $O$-aryl carbamate $\left[{ }^{11} \mathrm{C}\right] \mathbf{3 2}(26 \%), 5$-methoxytryptamine carbamate $\left[{ }^{11} \mathrm{C}\right] \mathbf{3 3}$ (84\%), and thiocarbamate $\left[{ }^{11} \mathrm{C}\right] \mathbf{3 4}(93 \%)$ could be radiolabeled, with trapping efficiencies ranging from $53-83 \%$. We suspect that mildly basic conditions and higher nucleophile concentrations improve the yields of 32-34 due to their sensitivity towards low temperature elimination. ${ }^{26}$ From tert-butyl iminophosphorane, $N$-hydroxysuccinimide-derived $\left[{ }^{11} \mathrm{C}\right] \mathbf{2 3}(99 \%)$ was also efficiently radiolabeled.

To further demonstrate the practicality of this technique $\left[{ }^{11} \mathrm{C}\right] \mathbf{3 5}$, an experimental antiarrhythmic compound, also containing the $B$-glucocerebrosidase activating moiety $N$-methyl$N$-(2-phenoxyethyl)amine, was isolated using a fully automated method (see ESI). ${ }^{27,28}\left[{ }^{11} \mathrm{C}\right] 35$ was labeled with $99 \%$ RCY starting from $15.7 \mathrm{GBq}$ of $\left[{ }^{11} \mathrm{C}^{\mathrm{C}} \mathrm{CO}_{2}\right.$, and obtained in an isolated yield of $33 \% \pm 10.6 \%(2.7 \pm 0.4 \mathrm{GBq})$ within $22 \mathrm{~min}$ from $\left[{ }^{11} \mathrm{C}_{\mathrm{CO}}\right.$ delivery. The fatty acid amide hydrolase inhibitor $\left[{ }^{11} \mathrm{C}\right]$ URB694 $\left(\left[{ }^{11} \mathrm{C}\right] \mathbf{2 5},\left[{ }^{11} \mathrm{C}\right] \mathrm{CURB}\right)$ is used in clinical research studies to investigate psychiatric illnesses and alcohol use disorder, and was prepared from cyclohexyliminophosphorane in $96 \% \pm 2 \%$ RCY (2:3 regioselectivity). ${ }^{29,30}$ From 25.9 GBq of $\left[{ }^{11} \mathrm{C}_{\mathrm{CO}_{2}}, 1.9 \mathrm{GBq} \pm 0.7 \mathrm{GBq}\right.$ of $\left[{ }^{11} \mathrm{C}\right] \mathrm{CURB}$ was obtained as the major isomer in $99 \%$ radiochemical purity, with an isolated decay corrected yield of $13 \% \pm 2 \%$, and a molar activity of $69 \mathrm{GBq} \cdot \mu \mathrm{mol}^{-1} \pm 37 \mathrm{GBq} \cdot \mu \mathrm{mol}^{-1}$ within $17 \mathrm{~min}$ from $\left[{ }^{11} \mathrm{C}^{-1} \mathrm{CO}_{2}\right.$ delivery. Lastly, the clinically approved sulfonylurea glibenclamide, currently used in the treatment of diabetes mellitus type 2 , and shown to reduce tissue damage in preclinical models for CNS injuries, was synthesized with $75 \% \pm 14 \% \mathrm{RCY} \cdot{ }^{31}\left[{ }^{11} \mathrm{C}\right]$ Glibenclamide $\left(\left[{ }^{11} \mathrm{C}\right] \mathbf{3 6}\right)$ is a substrate for organic anion-transporting polypeptide (OATP) transporter and can be used to study the integrity of the blood-brain barrier by non-invasive PET imaging. ${ }^{32,33}$ This radiopharmaceutical, which is currently synthesized in 
two-steps using $\left[{ }^{11} \mathrm{C}\right] \mathrm{CH}_{3} \mathrm{OTf}$, was efficiently labeled using an iminophosphorane precursor directly from $\left[{ }^{11} \mathrm{C}\right] \mathrm{CO}_{2}{ }^{34}$ Following purification $7.4 \pm 1.9 \mathrm{GBq}$ of $\left[{ }^{11} \mathrm{C}\right]$ glibenclamide was obtained with an isolated decay corrected yield of $62 \pm 16 \%$ from $25.9 \mathrm{GBq}$ of $\left[{ }^{11} \mathrm{C}\right] \mathrm{CO}_{2}$, and a molar activity of $59 \pm 0.06 \mathrm{GBq} \cdot \mu \mathrm{mol}^{-1}$ within 21 minutes from the beginning of synthesis. 


\section{Scheme 3: Carbon-11 Substrate Scope}

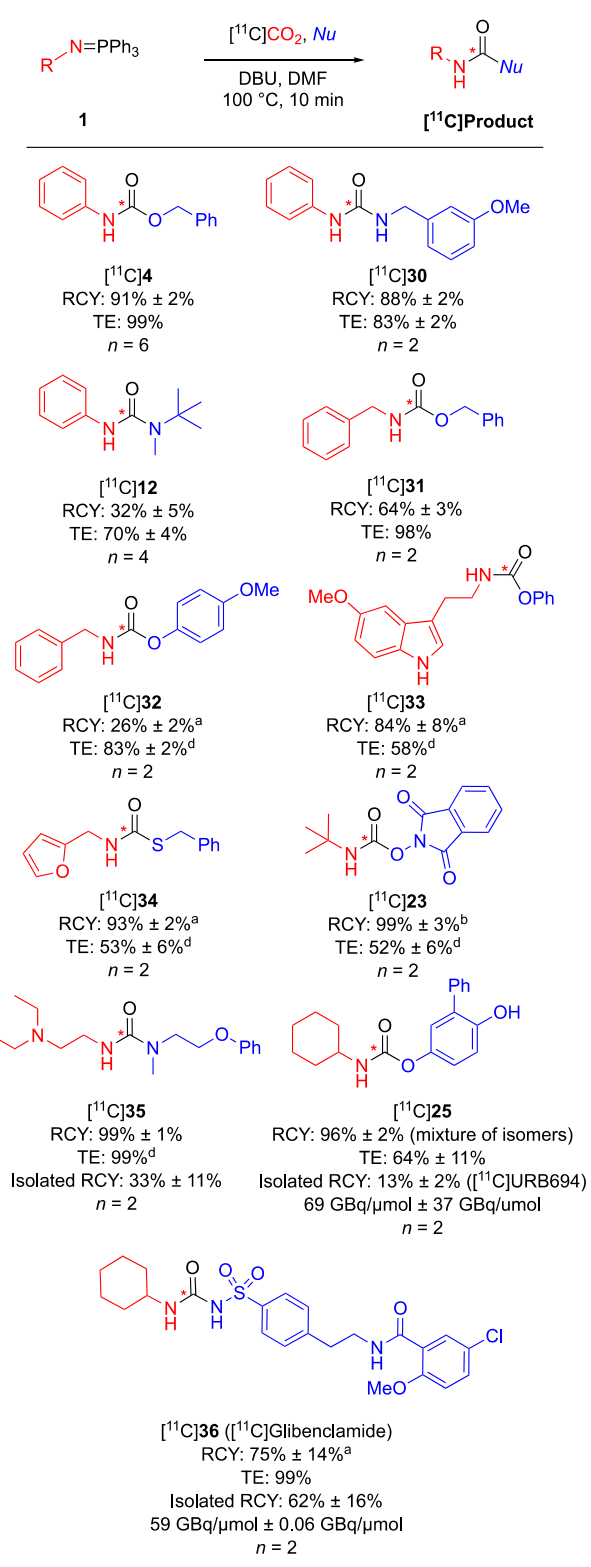

${ }^{a}$ DBU replaced with DABCO. ${ }^{b}$ DBU replaced with LHMDS. $^{\mathrm{c}} \mathrm{KO}^{t} \mathrm{Bu} .{ }^{\mathrm{d}}$ $\left[{ }^{11} \mathrm{C}\right] \mathrm{CO}_{2}$ trapped at $-60{ }^{\circ} \mathrm{C}$. See ESI for detailed procedures. $*$ indicates position of ${ }^{11} \mathrm{C}$. 


\section{Conclusion}

In conclusion, we have developed a methodology to synthesize several stable and radiolabeled functional groups using the interrupted aza-Wittig approach. The advantages of this method include direct $\left[{ }^{11} \mathrm{C}\right] \mathrm{CO}_{2}$-fixation using stable iminophosphorane precursors prepared from commercially available amines, diverse functional group selectivity, and applicability to relevant PET imaging agents. Radiopharmaceuticals are synthesized under mild reaction conditions with rapid synthesis times and using automated procedures to represent a novel strategy for labeling biologically relevant molecules. We anticipate this method contributing to the accessibility of indemand radiopharmaceuticals such as $\left[{ }^{11} \mathrm{C}\right] \mathrm{CURB}$ and $\left[{ }^{11} \mathrm{C}\right]$ glibenclamide, among others.

\section{Supporting Information}

Characterization data; experimental procedures; preparation of precursors; NMR spectra for compounds

\section{Author Information}

\section{Corresponding author}

Benjamin H. Rotstein - Department of Biochemistry, Microbiology and Immunology, and Department of Chemistry and Biomolecular Sciences, University of Ottawa, Ottawa, Ontario, Canada K1H 8M5; University of Ottawa Heart Institute, Ottawa, Ontario, Canada K1Y 4W7; orcid.org/0000-0001-9707-9357; Email: benjamin.rotstein@uottawa.ca

\section{Authors}


Uzair S. Ismailani - Department of Biochemistry, Microbiology and Immunology, University of Ottawa, Ottawa, Ontario, Canada KlH 8M5; University of Ottawa Heart Institute, Ottawa, Ontario, Canada K1Y 4W7.

Maxime Munch - Department of Biochemistry, Microbiology and Immunology, University of Ottawa, Ottawa, Ontario, Canada KlH 8M5; University of Ottawa Heart Institute, Ottawa, Ontario, Canada K1Y 4W7.

Braeden A. Mair - Department of Chemistry and Biomolecular Sciences, University of Ottawa, Ottawa, Ontario, Canada K1H 8M5; University of Ottawa Heart Institute, Ottawa, Ontario, Canada K1Y 4W7.

\section{ORCID}

Uzair S. Ismailani: 0000-0001-5102-6102

Maxime Munch: 0000-0002-3552-0538

Braeden A. Mair: 0000-0002-9180-8907

Benjamin H. Rotstein: 0000-0001-9707-9357

\section{Notes}

The authors declare no competing financial interest.

\section{Acknowledgements}

Financial and infrastructure support for this work were provided by the University of Ottawa Heart Institute (UOHI), and the Natural Sciences and Engineering Research Council of Canada (NSERC, RGPIN-2017-06167), The Canada foundation for Innovation (CFI, 36848), and the Ontario Ministry for Research, Innovation and Science (ER17-13-119). The authors are grateful to Dr. Taybeh Hadizad and Daniel Duan, in addition to the UOHI PET Radiochemistry core for isotope production. The authors are also grateful to Marcelo Muñoz and Gapisha Karunakaran for the isolation of chemical standards and preparation of precursors. 


\section{References}

(1) Ametamey, S. M.; Honer, M.; Schubiger, P. A. Molecular Imaging with PET. Chem. Rev. 2008, 108 (5), 1501-1516. https://doi.org/10.1021/cr0782426.

(2) Antoni, G. Development of Carbon-11 Labelled PET Tracers-Radiochemical and Technological Challenges in a Historic Perspective: Development of Carbon-11 Labelled PET Tracers. J. Label Compd. Radiopharm 2015, 58 (3), 65-72. https://doi.org/10.1002/jlcr.3258.

(3) Yang, L.; Scott, P. J. H.; Shao, X. [11C]Carbon Dioxide: Starting Point for Labeling PET Radiopharmaceuticals. In Carbon Dioxide Chemistry, Capture and Oil Recovery; Karamé, I., Shaya, J., Srour, H., Eds.; InTech, 2018. https://doi.org/10.5772/intechopen.72313.

(4) Rotstein, B. H.; Liang, S. H.; Placzek, M. S.; Hooker, J. M.; Gee, A. D.; Dollé, F.; Wilson, A. A.; Vasdev, N. 11C=O Bonds Made Easily for Positron Emission Tomography Radiopharmaceuticals. Chem Soc Rev 2016, 45 (17), 4708-4726. https://doi.org/10.1039/c6cs00310a.

(5) B, L.; G, A.; P, G.; C, H.; P, M.; K, N.; A, R.; H, S. Synthesis of L- and D-[Methyl11C]Methionine. J Nucl Med 1987, 28 (6), 1037-1040.

(6) Larsen, P.; Ulin, J.; Dahlstrøm, K.; Jensen, M. Synthesis of [11C]Iodomethane by Iodination of [11C]Methane. Applied Radiation and Isotopes 1997, 48 (2), 153-157. https://doi.org/10.1016/S0969-8043(96)00177-7.

(7) Link, J. M.; Krohn, K. A.; Clark, J. C. Production of [11C]CH3I by Single Pass Reaction of [11C]CH4 with I2. Nuclear Medicine and Biology 1997, 24 (1), 93-97. https://doi.org/10.1016/S0969-8051(96)00181-3.

(8) Jewett, M. A Simple Synthesis of [L1C]Methyl Triflate. 3.

(9) Delebecq, E.; Pascault, J.-P.; Boutevin, B.; Ganachaud, F. On the Versatility of Urethane/Urea Bonds: Reversibility, Blocked Isocyanate, and Non-Isocyanate Polyurethane. Chem. Rev. 2013, 113 (1), 80-118. https://doi.org/10.1021/cr300195n.

(10) Ghosh, A. K.; Brindisi, M.; Sarkar, A. The Curtius Rearrangement: Applications in Modern Drug Discovery and Medicinal Chemistry. ChemMedChem 2018, 13 (22), 23512373. https://doi.org/10.1002/cmdc.201800518.

(11) Wilson, A. A.; Garcia, A.; Houle, S.; Sadovski, O.; Vasdev, N. Synthesis and Application of Isocyanates Radiolabeled with Carbon-11. Chemistry - A European Journal 2011, 17 (1), 259-264. https://doi.org/10.1002/chem.201002345.

(12) Dheere, A. K. H.; Yusuf, N.; Gee, A. Rapid and Efficient Synthesis of [11C]Ureas via the Incorporation of [11C]CO2 into Aliphatic and Aromatic Amines. Chem. Commun. 2013, 49 (74), 8193-8195. https://doi.org/10.1039/C3CC44046J.

(13) Bongarzone, S.; Runser, A.; Taddei, C.; Dheere, A. K. H.; Gee, A. D. From [11C]CO2 to [11C]Amides: A Rapid One-Pot Synthesis via the Mitsunobu Reaction. Chem. Commun. (Camb.) 2017, 53 (38), 5334-5337. https://doi.org/10.1039/c7cc01407d.

(14) Mair, B. A.; Fouad, M. H.; Ismailani, U. S.; Munch, M.; Rotstein, B. H. RhodiumCatalyzed Addition of Organozinc Iodides to Carbon-11 Isocyanates. Org. Lett. 2020, 22 (7), 2746-2750. https://doi.org/10.1021/acs.orglett.0c00729.

(15) Saylik, D.; Horvath, M. J.; Elmes, P. S.; Jackson, W. R.; Lovel, C. G.; Moody, K. Preparation of Isocyanates from Primary Amines and Carbon Dioxide Using Mitsunobu Chemistry ${ }^{1}$. J. Org. Chem. 1999, 64 (11), 3940-3946. https://doi.org/10.1021/jo982362j. 
(16) Molina, P. I.; Alajarin, M.; Arques, A. Convenient Improved Syntheses of Isocyanates or Isothiocyanates from Amines. Synthesis 1982. https://doi.org/10.1055/s-1982-29877.

(17) Fresneda, P. M.; Molina, P. Application of Iminophosphorane-Based Methodologies for the Synthesis of Natural Products. Synlett 2004, 2004 (01), 1-17. https://doi.org/10.1055/s-2003-43338.

(18) Eguchi, S.; Matsushita, Y.; Yamashita, K. THE AZA-WITTIC REACTION IN HETEROCYCLIC SYNTHESIS. A REVIEW. Organic Preparations and Procedures International 1992, 24 (2), 209-243. https://doi.org/10.1080/00304949209355702.

(19) van Tilburg, E. W.; Windhorst, A. D.; van der Mey, M.; Herscheid, J. D. M. One-Pot Synthesis of [11C]Ureas via Triphenylphosphinimines. J Label Compd Radiopharm 2006, 49 (4), 321-330. https://doi.org/10.1002/jlcr.1052.

(20) Del Vecchio, A.; Caillé, F.; Chevalier, A.; Loreau, O.; Horkka, K.; Halldin, C.; Schou, M.; Camus, N.; Kessler, P.; Kuhnast, B.; Taran, F.; Audisio, D. Late-Stage Isotopic Carbon Labeling of Pharmaceutically Relevant Cyclic Ureas Directly from $\mathrm{CO}_{2}$. Angew. Chem. Int. Ed. 2018, 57 (31), 9744-9748. https://doi.org/10.1002/anie.201804838.

(21) Del Vecchio, A.; Talbot, A.; Caillé, F.; Chevalier, A.; Sallustrau, A.; Loreau, O.; Destro, G.; Taran, F.; Audisio, D. Carbon Isotope Labeling of Carbamates by Late-Stage [ $\left.{ }^{11} \mathrm{C}\right]$, [ ${ }^{13} \mathrm{C}$ ] and $\left[{ }^{14} \mathrm{C}\right]$ Carbon Dioxide Incorporation. Chem. Commun. 2020, 56 (78), 1167711680. https://doi.org/10.1039/D0CC05031H.

(22) Villiers, C.; Dognon, J.-P.; Pollet, R.; Thuéry, P.; Ephritikhine, M. An Isolated CO2 Adduct of a Nitrogen Base: Crystal and Electronic Structures. Angewandte Chemie International Edition 2010, 49 (20), 3465-3468. https://doi.org/10.1002/anie.201001035.

(23) Hulla, M.; Dyson, P. J. Pivotal Role of the Basic Character of Organic and Salt Catalysts in $\mathrm{C}-\mathrm{N}$ Bond Forming Reactions of Amines with $\mathrm{CO}$ 2. Angew. Chem. Int. Ed. 2020, 59 (3), 1002-1017. https://doi.org/10.1002/anie.201906942.

(24) Rolph, M. S.; Markowska, A. L. J.; Warriner, C. N.; O’Reilly, R. K. Blocked Isocyanates: From Analytical and Experimental Considerations to Non-Polyurethane Applications. Polym. Chem. 2016, 7 (48), 7351-7364. https://doi.org/10.1039/C6PY01776B.

(25) Hutchby, M.; Houlden, C. E.; Ford, J. G.; Tyler, S. N. G.; Gagné, M. R.; Lloyd-Jones, G. C.; Booker-Milburn, K. I. Hindered Ureas as Masked Isocyanates: Facile Carbamoylation of Nucleophiles under Neutral Conditions. Angew. Chem. Int. Ed. Engl. 2009, 48 (46), 8721-8724. https://doi.org/10.1002/anie.200904435.

(26) Derasp, J. S.; Beauchemin, A. M. Rhodium-Catalyzed Synthesis of Amides from Functionalized Blocked Isocyanates. ACS Catal. 2019, 9 (9), 8104-8109. https://doi.org/10.1021/acscatal.9b02641.

(27) Zheng, J.; Jeon, S.; Jiang, W.; Burbulla, L. F.; Ysselstein, D.; Oevel, K.; Krainc, D.; Silverman, R. B. Conversion of Quinazoline Modulators from Inhibitors to Activators of $\beta$-Glucocerebrosidase. J. Med. Chem. 2019, 62 (3), 1218-1230. https://doi.org/10.1021/acs.jmedchem.8b01294.

(28) Jr, J. R. S.; III, C. P. J. Method of Treating Cardiac Disorders with N-(Aryloxyalkyl)-N'(Aminoalkyl)Ureas. US4500529A, February 19, 1985.

(29) Wilson, A. A.; Garcia, A.; Parkes, J.; Houle, S.; Tong, J.; Vasdev, N. [11C]CURB: Evaluation of a Novel Radiotracer for Imaging Fatty Acid Amide Hydrolase by Positron Emission Tomography. Nuclear Medicine and Biology 2011, 38 (2), 247-253. https://doi.org/10.1016/j.nucmedbio.2010.08.001. 
(30) Best, L. M.; Williams, B.; Le Foll, B.; Mansouri, E.; Bazinet, R. P.; Lin, L.; De Luca, V.; Lagzdins, D.; Rusjan, P.; Tyndale, R. F.; Wilson, A. A.; Hendershot, C. S.; Heilig, M.; Houle, S.; Tong, J.; Kish, S. J.; Boileau, I. Lower Brain Fatty Acid Amide Hydrolase in Treatment-Seeking Patients with Alcohol Use Disorder: A Positron Emission Tomography Study with [C-11]CURB. Neuropsychopharmacology 2020, 1-8. https://doi.org/10.1038/s41386-020-0606-2.

(31) Kurland, D. B.; Tosun, C.; Pampori, A.; Karimy, J. K.; Caffes, N. M.; Gerzanich, V.; Simard, J. M. Glibenclamide for the Treatment of Acute CNS Injury. Pharmaceuticals (Basel) 2013, 6 (10), 1287-1303. https://doi.org/10.3390/ph6101287.

(32) Langer, O. Use of PET Imaging to Evaluate Transporter-Mediated Drug-Drug Interactions. The Journal of Clinical Pharmacology 2016, 56 (S7), S143-S156. https://doi.org/10.1002/jcph.722.

(33) Tournier, N.; Saba, W.; Cisternino, S.; Peyronneau, M.-A.; Damont, A.; Goutal, S.; Dubois, A.; Dollé, F.; Scherrmann, J.-M.; Valette, H.; Kuhnast, B.; Bottlaender, M. Effects of Selected OATP and/or ABC Transporter Inhibitors on the Brain and WholeBody Distribution of Glyburide. AAPS J 2013, 15 (4), 1082-1090. https://doi.org/10.1208/s12248-013-9514-2.

(34) Caillé, F.; Gervais, P.; Auvity, S.; Coulon, C.; Marie, S.; Tournier, N.; Kuhnast, B. Automated Two-Step Manufacturing of [11C]Glyburide Radiopharmaceutical for PET Imaging in Humans. Nuclear Medicine and Biology 2020, 84-85, 20-27. https://doi.org/10.1016/j.nucmedbio.2019.12.008. 